\title{
TYPE IX AND TYPE II COLLAGENS ARE COORDINATELY EXPRESSED DURING CHICK LIMB DEVELOPMENT
}

\author{
Tomoatsu Kimura ${ }^{1}$, Natsuo Yasui $^{2}$, Shigeyuki Wakitani $^{1}$, Nobuhito Araki ${ }^{1}$ and \\ KEIRO ONO ${ }^{1}$ \\ 'Department of Orthopaedic Surgery, Osaka University Medical School, Fukushimaku, Fukushima, Osaka \\ 553 , and ${ }^{2}$ Department of Orthopaedic Surgery, National Defense Medical College, Namiki, Tokorozawa, \\ Saitama 359, Japan
}

\begin{abstract}
Changes in the level of type IX and type II collegen mRNA were examined during the course of chick limb development in vivo using cloned cDNA probes. Substantial amounts of type IX and type II collagen mRNA were detected at stage 26, concurrently with the chondrogenic differentiation of limb mesenchyme. Subsequently, the amounts of type IX and type II collagen mRNA showed parallel and marked increases corresponding to the progressive accumulation of cartilage matrix in the limb. Type IX and type II collagen synthesis also increased coinciding with a dramatic increase in their respective mRNAs. The present study suggests that type IX and type II collagens are coordinately expressed during the course of limb cartilage differentiation, which would enable the formation of a very precise temporal and spatial arrangement of cartilage matrices.
\end{abstract}

Differentiation of cartilage is an important key event in vertebrate limb development and has been described extensively $(4,8,21,22$, 24). Loosely packed mesenchyme cells of chick limb buds start to condensate in the limb core at stage 22 (6). By stage $25 / 26$, these cells begin to secrete matrix macromolecules making a mold which is subsequently replaced by bone. Biochemically, this process of cartilage differentiation is characterized by the initiation of type II, type IX, and type XI collagen synthesis and cessation of type I collagen synthesis $(9,14,27)$. The molecular regulation of these events is still obscure, but to analyze it will be of vital importance for understanding the mechanism of cartilage differentiation.

Recently, the availability of cloned cDNA

Abbreviations: $1 \times \mathrm{SSC}, 0.15 \mathrm{M} \mathrm{NaCl}$ in $0.015 \mathrm{M}$ sodium citrate buffer, $\mathrm{pH} 7.0 ;$ SDS, sodium dodecyl sulfate probes complementary to mRNA for collagens and cartilage proteoglycan has made it possible to analyze their gene expression during limb cartilage differentiation $(10-12,15)$. In the work presented here, we have used cDNA probes coding for type IX and type II collagens to examine the mRNA levels in chick limbs undergoing cartilage differentiation. Changes in collagen synthesis were also examined. Our results suggest that type IX and type II collagens are coordinately expressed during the process of cartilage differentiation. This is quite reasonable since type IX and II collagens are covalently cross-linked $(3,25)$ and would participate coordinately in the formation of cartilage structure.

\section{MATERIALS AND METHODS}

\section{RNA Extraction}

Forelimbs (wing of wing bud) were excised 
from chick embryos at stage 22 to 32 (6). After homogenization with a Polytron homogenizer, the total RNA was prepared by guanidine thiocyanate extraction/CsCl density gradient centrifugation procedure (2).

\section{Dot Blot and Northern Blot Hybridizations}

Dot blots of total RNA were performed as described (5). For Northern blot analysis, the total cellular RNA ( 7 to $10 \mu \mathrm{g}$ ) from different stage forelimbs was electrophoresed in $0.8 \%$ agarose gels in the presence of formamide/ formaldehyde and transferred onto nitrocellulose filters. The filters were hybridized to nick-translated DNA as described previously (23). After hybridization in $5 \times \operatorname{SSC}(0.15 \mathrm{M}$ $\mathrm{NaCl}$ in $0.015 \mathrm{M}$ sodium citrate buffer, $\mathrm{pH} 7.0$ ) and $1 \% \mathrm{~N}$-lauroylsarcosine at $65^{\circ} \mathrm{C}$, the filters were washed twice in $3 \times \mathrm{SSC}$ and $0.5 \% \mathrm{~N}$-lauroylsarcosine, twice in $3 \times \mathrm{SSC}$ at $65^{\circ} \mathrm{C}$, and exposed to Kodak Royal X-Omat film at $-70^{\circ} \mathrm{C}$. The levels of hybridizable RNA sequences were quantified by scanning the dot blot autoradiograms with a scanning densitometer (CS-910 scanner, Shimadzu).

The collagen cDNA probes used as hybridization probes were pYN1738, a 3294 base-pair cDNA encoding part of the $\alpha 1$ (IX) collagen subunit, pYN2142, a 603 base-pair cDNA encoding part of the $\alpha 1$ (II) procollagen subunit, and pYN 535, a 530 base-pair cDNA encoding part of the $\alpha 2(\mathrm{I})$ procollagen subunit $(17,18)$ (kindly provided by Drs Y. Ninomiya and B. R. Olsen, Harvard Medical School).

\section{Analysis of Collagen Synthesis}

Collagen newly synthesized by the chick forelimbs was analyzed as previously reported (9). The excised forelimbs from stage 24 to 32 chick embryos were labeled in vitro for $6 \mathrm{~h}$ at $37^{\circ} \mathrm{C}$ with $\left[{ }^{14} \mathrm{C}\right]$ proline $(20 \mu \mathrm{Ci} / \mathrm{ml}$, New England Nuclear) and the synthesized collagens were extracted and analyzed by SDSpolyacrylamide gel electrophoresis followed by fluorography $(1,13)$. To quantify the collagen phenotype, the fluorographic bands were traced on the dried gels, cut out into scintillation vials, and hydrolyzed in $0.5 \mathrm{ml}$ of $0.4 \mathrm{M}$ $\mathrm{NaOH}$ at $56^{\circ} \mathrm{C}$ for $24 \mathrm{~h}$. After neutralization with $\mathrm{HCl}$, the radioactivity of the individual bands was counted in $10 \mathrm{ml}$ of PCS II (Amer- sham).

\section{RESULTS AND DISCUSSION}

The cDNA fragments used as hybridization probes are shown in Fig. 1. The restriction fragments of pYN 535 and pYN 2142 were selected so as to show the least possible crosshybridization as described previously (7). The whole insert was used for $\mathrm{pYN} 1738$ because it did not show any cross-hybridization under the present hybridization conditions (see below).

\section{Type IX and Type II Collagen mRNA Levels during Limb Development}

To examine how the levels of type IX collagen and type II collagen RNA change during limb development, total cellular RNAs isolated from chick forelimbs at stages $24,26,28,30$, 32 of development were probed with type IX- and type II-collagen-specific [ $\left.{ }^{32} \mathrm{P}\right]$-labeled cDNAs. This procedure allowed us to quantify relative changes in total hybridizable type IX and type II collagen mRNAs.

No detectable amounts of mRNA hybridized to type IX collagen cDNA was present at stage 24 (Fig. 2), which is a stage prior to the occurrence of morphological indications of chondrogenic differentiation by the mesenchyme cells. By stage 26 , which corresponds

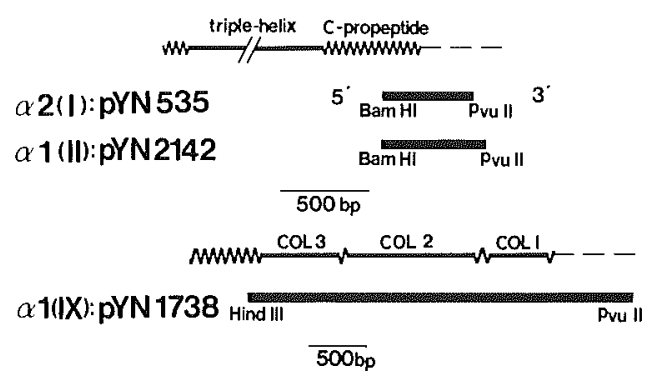

Fig. 1 Diagram showing the location of collagen cDNA probes. Regions used as hybridization probes are indicated by wide black bars. The direction of the coding strand of the probe is from left to right, as indicated by the $5^{\prime}$ and $3^{\prime}$ notation. The $3^{\prime}$ untranslated portion is indicated by a dashed line. Three collagenous domains (COL 1, COL 2 and COL 3 ) of type IX collagen are indicated according to reference 17 . 


\section{$\alpha 1(\mathrm{IX})$}

$\alpha 1$ (II)

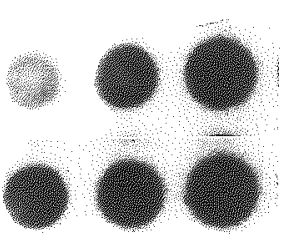

$\begin{array}{llllll}\text { stage } & 24 & 26 & 28 & 30 & 32\end{array}$

Fig. 2 Dot hybridization analysis of $\alpha 1$ (IX) collagen and $\alpha$ (II) procollgen mRNA levels in the developing chick limbs. Two $\mu \mathrm{g}$ of total RNA extracted at the stage indicated were blotted on nitrocellulose and hybridized to the indicated nick-translated probes.

to the onset of overt chondrogenesis $(4,21)$, substantial amounts of type IX collagen mRNA were detected. This initiation of type IX collagen mRNA accumulation coincided with a dramatic increase in type II collagen mRNA accumulation (Fig. 2). The amounts of type IX and type II collagen mRNA began to increase dramatically after this stage which paralleled the progressive accumulation of cartilage matrix in the limb core. Judging from the results of densitometric scanning, the level of mRNA at stage 32 is approximately 12 times higher for type IX collagen and 7 times higher for type II collagen than at stage 26. It should be noted, however, that a very low level of type II collagen mRNA was detected at stage 24, prior to the onset of chondrogenesis as reported previously (11, 12). This low level of mRNA was not detectable in the following Northern blot analysis because of the lower sensitivity of the Northern blot hybridization method.

To confirm that the observed increase in type IX and type II collagen mRNA levels was not an effect of cross-hybridization to other collagenous mRNA species or an artifact of the RNA preparation, Northern blot hybridization was performed. Although the relative amounts of each mRNA species from different stages are not precisely shown in Fig. 3, it was obvious that the $\alpha 1$ (IX) collagen probe was capable of hybridizing to two RNA bands of approximately 4.2 kilobases and 3.5 kilobases, and the $\alpha 1$ (II) collagen probe to one RNA band of 5.9 kilobases. The presence of

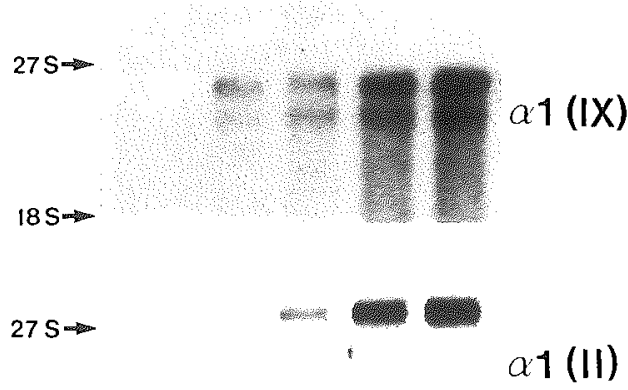

$18 S \rightarrow$

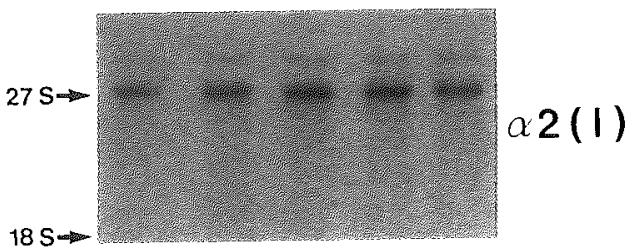

stage $\begin{array}{lllll}24 & 26 & 28 & 30 & 32\end{array}$

Fig. 3 Northern blot hybridization of total RNA. Approximately 7 to $10 \mu \mathrm{g}$ of total RNA were electrophoresed in a $0.8 \%$ agarose gel, blotted onto nitrocellulose, and hybridized to the indicated probes. Chicken sternal cartilage $18 \mathrm{~S}$ and $27 \mathrm{~S}$ rRNAs were used as RNA size markers.

two $\alpha 1$ (IX) mRNAs of different size is probably due to differences in the utilization of multiple polyadenylylation sites as previously documented (17). There was no cross-hybridization to other collagen mRNA species. The finding that the relative mRNA level of the $\alpha 2$ (I) chain remained approximately constant is not surprising since limbs at stages between 24 and 32 predominantly consist of non-cartilaginous tissue which synthesizes type I collagen. In addition, $\alpha 2$ (I) mRNA is present even in cartilage where no $\alpha 2$ (I) collagen chain synthesis is detectable (20).

\section{Type IX and Type II Collagen Synthesis}

Newly synthesized collagens were analyzed by sodium dodecyl sulfate (SDS)-polyacrylamide gel electrophoresis, and the changes in collagen phenotype are summarized in Fig. 4. Utilizing the known chain composition of collagen type I, II, and IX, the relative amount of each collagen was calculated from the radioactivity of electrophoretic bands (28). The colla- 


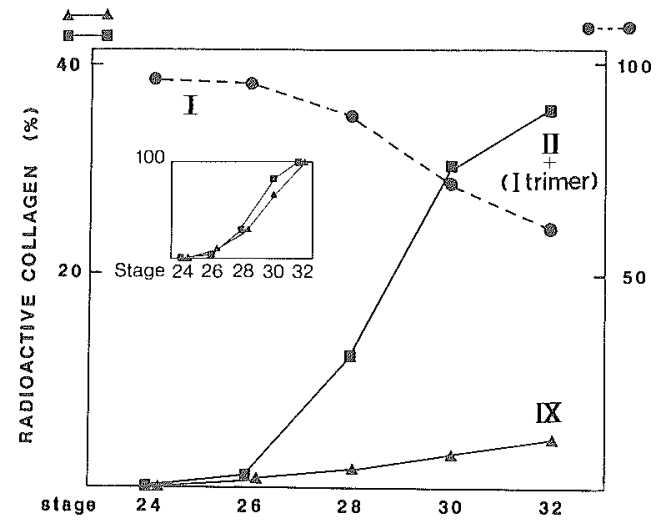

Fig. 4 Change in collagen phenotype during chick limb development. Collagen from stage 24-32 forelimbs was fractionated by electrophoresis, and the radioactive bands were removed from the gels and counted as described under Materials and Methods. The amount of each collagen type was calculated according to reference 28 . Because of the method of calculation, a small proportion of type I trimer is included in the type II collagen. Values are expressed as the mean from duplicate experiments. Inset: The amount of radioactive type IX and type II collagens at each point is expressed as an amount relative to that present at stage 32 , which was arbitrarily set to 100 .

gen synthesized by stage 24 limb buds was predominantly type I, while neither type IX nor type II collagen was detected. Type IX and type II collagen synthesis was first detected at stage 26 , when phenotypically identifiable cartilage is first detected in the limb. Subsequently, the synthesis of type IX collagen increased dramatically, parallel to an increase in type Ii collagen synthesis. This dramatic and parallel increase in type IX and type II collagen synthesis is further obvious when the amount of radioactive collagens at each point is expressed as an amount relative to that present at stage 32 (Fig. 4, inset). These results suggest that the expression of type IX and type II collagens is coordinately regulated during the development of the chick limb. Since the dramatic increase in the collagen synthesis paralleled the increase in the respective mRNA levels, their regulation must, at least in part, be pretranslational.

Further support for the assumption that the expression of type IX and type II collagens is coordinately regulated can be derived from our previous observation (28). We analyzed collagen synthesis during the growth of chick chondrocytes in retinoic acid or 5-bromo-2'deoxyuridine. The synthesis of type IX and type II collagens showed parallel decrease after treatment with these two different modulating agents. Thus, these collagens appear to form a group of coordinately regulated molecules associated with the differentiated chondrogenic phenotype.

The function of type IX collagen is still obscure. However, its localization within the cartilage is suggestive of a structural role. It has been demonstrated that type IX collagen is closely associated with the fibrils formed by type II collagen molecules (16). In addition, van der Rest and Mayne (25), and Eyre et al. (3) have demonstrated the existence of a covalent cross-link between type IX collagen and type II collagen. This finding led van der Rest and Mayne to the hypothesis that type IX collagen interacts with the type II fibril, with lateral association between the type II triplehelices and C-terminal 2/3 of type IX collagen molecules (25). The opposite end of the type IX collagen molecule, the $\mathrm{N}$-terminal globular domain, is basic ( $\mathrm{II}=9.7)(26)$ and may serve as a junction site with other matrix components, such as cartilage glycosaminoglycan (19). Thus, type IX collagen is thought to play a role in the interaction between cartilage matrix components.

As demonstrated in the present study, the expression of type IX and type II collagens is coordinately regulated, as shown by parallel changes in mRNA and protein synthesis during the course of limb development. Furthermore, Kosher et al. (10) have demonstrated that the cartilage proteoglycan core protein and type II collagen genes are coordinately regulated during chondrogenesis. It now seems quite likely that these distinct genes of cartilage matrix macromolecules are coordinately regulated during limb cartilage differentiation, which enables these matrix components to form the very precise temporal and spatial arrangement necessary for the cartilage structure formation.

We are grateful to Drs Y. Ninomiya and B. R. Olsen for generously providing cDNA probes.

Received for publication 13 June 1988; and in revised form 30 Jume 1988 


\section{REFERENCES}

1. Bonner W. M. and Laskey R. A. (1974) A film detection method for tritium-labelled proteins and nucleic acids in polyacrylamide gels. Eur. $J$. Biochem. 46, 83-88

2. Chirgwin J. M., Przybyla A. E., MacDonald R. J. and RutTer W. J. (1979) Isolation of biologically active ribonucleic acid from sources enriched in ribonuclease. Biochemistry $\mathbf{1 8}$ 5294-5299

3. Eyre D. R., Apon S., Wu J.-J., Ericsson L. H. and WALSH K. A. (1987) Collagen type IX: Evidence for covalent linkages to type II collagen in cartilage. FEBS Lett. 220, 337-341

4. Goel S. C. (1970) Electron microscopic studies on developing cartilage. I. The membrane system related to the synthesis and secretion of extracellular materials. J. Embryol. Exp. Morphol. 23, 169-184

5. Goldring M. B., Sandell L. J., Stephenson M. L. and KRANE S. M. (1986) Immune interferon suppresses levels of procollagen mRNA and type II collagen synthesis in cultured human articular and costal chondrocytes. J. Biol. Chem. 261, 9049-9056

6. Hamburger V. and Hamilton H. L. (1951) A series of normal stages in the development of the chick embryo. J. Morphol. 88, 49-92

7. Hayashi M., Ninomiya Y., Parsons J,, Hayashi K., Olsen B. R. and Trelstad R. L. (1986) Differential localization of mRNAs of collagen types I and II in chick fibroblasts, chondrocytes, and corneal cells by in situ hybridization using cDNA probes. J. Cell Biol. 102, 23022309

8. JURAND A. (1965) Ultrastructural aspects of early development of the forelimb buds in the chick and mouse. Proc. R. Soc. Lond. Ser. B, 162, 387-405

9. Kimura T., Yasul N., Ohsawa S. and Ono K. (1985) Biosynthesis of type IX collagen during chick limb development. Biochem. Biophys. Res. Commun. 130, 746-752

10. Kosher R. A., Gay S. W., Kamanitz J. R., KulyK W. M., Rodgers B. J., SaI S., Tanaka T. and TANZER M. L. (1986) Cartilage proteoglycan core protein gene expression during limb cartilage differentiation. Develop. Biol. 118, 112-117

11. Kosher R. A., Kulyk W. M. and GAY S. W. (1986) Collagen gene expression during limb cartilage differentiation. J. Cell Biol. 102, 11511156

12. Kravis D. and Upholt W. B. (1985) Quantitation of type II procollagen mRNA levels during chick limb cartilage differentiation. Develop. Biol. 108, 164-172

13. Laemmli U. K. (1970) Cleavage of structural proteins during the assembly of the head of bacteriophage T4. Nature 227, 680-685

14. Linsenmayer T. F., Toole B. R. and Trelstad R. L. (1973) Temporal and spatial transitions in collagen types during embryonic chick limb development. Develop. Biol. 35, 232-239

15. Merlino G. T., McKeon C, de Crombrugghe B. and Pastan I. (1983) Rugulation of the expression of genes encoding types I, II and III collagen during chick embryonic development. J. Biol. Chem. 258, 10041-10048

16. Müller-Glauser W., Humbel B., Glatt M. SträUli P., Winterhalter K. H. and BruckNER P. (1986) On the role of type IX collagen in the extracellular matrix of cartilage: Type IX collagen is localized to intersections of collagen fibrils. J. Cell Biol. 102, 1931-1939

17. Ninomiya Y. and Olsen B. R. (1984) Synthesis and characterization of cDNA encoding a cartilage-specific short collagen. Proc. Natl. Acad. Sci. USA 81, 3014-3018

18. Ninomiya Y., Showalter A. M., van der Rest M., Seidah N. G., Chrétien M. and Olsen B. R. (1984) Structure of the carboxyl propeptide of chicken type II procollagen determined by DNA and protein sequence analysis. Biochemistry 23, 617-624

19. Olsen B. R., Gerecke D., Gordon M., Green G., Kimura T,, Konomi H., Muragaki Y., NinomiYa Y., Nishimura I, and Sugrue S. (1988) A new dimension in the extracellular matrix. In Collagen: Biochemistry, Biotechnology and Molecular Biology (ed. OLSEN B. R. and NImNi M. E.) Vol. IV, CRC Press (in press)

20. SaXe S. A., Lukens L. N. and Pawlowski P. J. (1985) Changes in the nuclear and cytoplasmic levels of type I and type II collagen RNAs during growth of chondrocytes in 5-bromo-2'deoxyuridine. J. Biol. Chem. 260, 3812-3819

21. Searls R. L., Hilfer S. R. and Mirow S. M. (1972) An ultrastructural study of early chondrogenesis in the chick wing bud. Develop. Biol. 28, 123-137

22. Summerbell D. and Wolpert L. (1972) Cell density and cell division in the early morphogenesis of the chick wing. Nature New Biol. 239, 24-26

23. Thomas P. S. (1980) Hybridization of denatured RNA and small DNA fragments transferred to nitrocellulose. Proc. Natl. Acad. Sci. USA 77, 5201-5205

24. Thorogood P. V. and HinchClifFe J. R. (1975) An analysis of the condensation process during chondrogenesis in the embryonic chick hind limb. J. Embryol. Exp. Morphol. 33, 581-606

25. VAN DER Rest M. and MAYNe R. (1988) Type IX collagen proteoglycan from cartilage is covalently cross-linked to type II collagen. J. Biol. 
Chem. 263, 1615-1618

26. Vasios G., Nishimura I., Konomi H., VAN DeR Rest M., Ninomiya Y. and Olsen B. R. (1988) Cartilage type IX collagen-proteoglycan contains a large amino-terminal globular domain encoded by multiple exons. J. Biol. Chem. 263, 2324-2329

27. von Der Mark H., von Der Mark K. and GaY S. (1976) Study of differential collagen synthesis during development of the chick embryo by immunofluorescence. I. Preparation of collagen type I and type II specific antibodies and their application to early stages of the chick embryo. Develop. Biol. 48, 237-249

28. Yasui N., BenYa P. D. and Nimni M. E. (1986) Coordinate regulation of type IX and type II collagen synthesis during growth of chick chondrocytes in retinoic acid or 5bromo-2'-deoxyuridine. J. Biol. Chem. 261, 7997-8001 